\title{
A Three-Year Comparison of Natural Gas and Diesel Transit Buses
}

Cameron Beach and Michael Cooke, Sacramento Regional Transit District Tracy Daly, Metrolink, Los Angeles

Bruce Finley, SunLine Transit Agency, Palm Springs

Cis Leroy, Transit Industry Consultant

\begin{abstract}
$\overline{\text { Abstract }}$
This article details the experiences of two California public transit agencies, Sacramento Regional Transit District (RT) and SunLine Transit Agency, which replaced aging diesel buses with new compressed natural gas (CNG) buses in 1994. It compares the operating characteristics and costs of 170 CNG buses (with the same engine-chassis configuration) and 73 diesel buses in service at the same time. Equipment was tested over a three-year period for a total of 22.2 million miles.

The data indicate that labor, parts, and fuel for diesel equipment cost more than for CNG buses. Both agencies also achieved significant savings in hazardous waste disposal. The study indicates payback of the incremental costs of CNG equipment is realized in six to eight years, and that both communities benefit from public transit's clean air leadership.
\end{abstract}

\section{Introduction}

At the beginning of their respective transitions to alternative fuel, Sacramento RT and SunLine were operating aging fleets of diesel buses in need of replacement. Both public transit agencies began independent research into 
alternatives. Each decided $\mathrm{CNG}$ was the best choice at the time. It was mere coincidence that the agencies chose the same transit bus manufacturer, chassis, and engine configuration, albeit determined in great part by the availability of California Air Resources Board (CARB)-certified engine choices.

While the air quality advantages of CNG fuel have been well documented, prior to this research project, no large-sample study compared the maintenance costs of CNG with diesel in a head-to-head test. Reports at the onset of the alternative fuels movement featured small samples and/or short operating periods.

These figures were collected from two transit agencies over a three-year period. Buses operated in equal service and maintenance environments.

\section{Background}

RT began providing service in 1973 in the growing Sacramento, California, region. The agency currently operates in a 418-square-mile area. It serves a population of 1,060,000 with 60 bus routes and light rail. The transit fleet consists of 209 buses and 36 light rail vehicles. Combined ridership totals $24,802,000$ unlinked trips per year. Overall, annual operating expense is $\$ 55$ million for all agency functions.

RT's service area has been classified by the U.S. Environmental Protection Agency as a severe nonattainment zone for air quality. As a result, RT is committed to eventually replacing all diesel buses with lower emissions CNG vehicles.

SunLine began service in 1977 in the Coachella Valley in southern California. The valley, comprised of Palm Springs and eight other resort cities, has a population of more than 260,000 . SunLine's service area is approximately 406 square miles.

Though it once had the dubious distinction of operating one of the oldest fleets in the country, in 1994 SunLine replaced its entire fleet with new CNG buses. Ridership now exceeds 3,500,000 per year. The agency's overall annual operating budget is $\$ 11$ million.

Both CNG fleets surpass CARB's stringent 1994 emissions standards, pri- 
marily in reduction of particulate matter and $\mathrm{NO}_{\mathrm{x}}$ emissions. Both agencies operate fueling stations on-site; both systems have experienced steadily increasing ridership over the last few years.

\section{Profile of Fleets}

RT operated 136 40-foot Orion V CNG buses built since 1993 in fixedroute service. The buses operated approximately 5.7 million miles per year, each averaging about 42,000 miles per year. The 73-bus diesel fleet operated approximately 50 percent less.

SunLine operated a 100 percent CNG fleet of 3440 -foot Orion V buses built in 1993 and 5 29-foot El Dorado buses in fixed-route service. This report includes data for the Orion buses only. Each SunLine vehicle averaged about 43,500 miles per year for a total of nearly 1.5 million miles. The study fleet composition is listed in Table 1.

Both agencies operated fully accessible fleets and complementary paratransit services according to the Americans with Disabilities Act. The common CNG fleet configurations studied in this report are model years 1993/94/96 Orion $\mathrm{V}$ buses powered by six-cylinder Cummins L10G engines, original equipment manufactured for dedicated CNG operation. All buses were equipped with bike racks to allow for multimodal travel, wheelchair lifts, and air-conditioning, due to extreme summer air temperatures.

The diesel buses analyzed were model years 1985/90 Gillig powered by Detroit Diesel 6V92 series engines. These two-stroke diesel engines are the most common source of bus power in the U.S. public transit system.

\section{Methodology}

This report was prepared by researching the maintenance records and databases of both agencies. RT and SunLine use different computer-based programs to track cost categories and have different philosophies on tracking the work order process as applied to cost allocations. Those differences were man- 


\begin{tabular}{|l|c|c|c|c|l|}
\hline \multicolumn{5}{|c|}{ Study Fleet Composition } \\
\hline Fleet & \multicolumn{2}{|c|}{ Quantity } & Year & \multicolumn{2}{c|}{ Manufacturer } \\
\hline & Diesel & CNG & & Chassis & Engine \\
\hline RT & 48 & & 1990 & Gillig & Detroit Diesel 6V92TA \\
\hline & 25 & & 1985 & Gillig & Detroit Diesel V92TB \\
\hline & & 41 & 1996 & Orion & Cummins L10G/280 \\
\hline & & 20 & 1994 & Orion & Cummins L10G/240 \\
\hline & & 75 & 1993 & Orion & Cummins L10G/240 \\
\hline SunLine & & 34 & 1993 & Orion & Cummins L10G/240 \\
\hline Total & 73 & 170 & & & \\
\hline
\end{tabular}

ually adjusted in the final analysis and cost breakdown so data could be collated into matching categorical descriptions. Final totals for CNG-to-CNG cost performance between the two agencies indicate the method was successful.

\section{Assumption 1: New Buses versus Old}

This study compared new CNG buses to old diesel equipment. As expected, it was difficult to quantify the maintenance advantage of a new bus compared to one aged in service. Certainly, a new diesel bus would show maintenance cost advantages over an old diesel bus. But an agency attempting to discontinue diesel purchases can still use the CNG cost data to make comparisons to similar vintage diesel.

All of the buses show increasing annual expense as each of the fleets age. But, the margin of cost reductions of CNG buses over diesel continues to grow, as explained in the Year-to-Year Costs section (below).

\section{Assumption 2: Characterization of Operating Environments}

Sacramento and the Coachella Valley have similar ambient temperatures, weather, and primarily flat service terrain. RT and SunLine have comparable transit duty demands on maintainability and reliability. Therefore, this factor was considered negligible in collating the cost data. 


\section{Assumption 3: Weight Disadvantages of CNG Buses}

A CNG bus can weigh 2,500 pounds more than a diesel bus because of the necessary storage cylinders. Yet this presented no problem to either agency and operational cost savings were still substantial. (Tire wear was included in the "parts" category.)

The intuitive conclusion for increased brake wear due to the resulting increased inertial forces was actually found to have decreased by using stateof-the-art transmissions employing a speed retarder for additional deceleration assistance. This same property would apply to new diesel buses as well.

\section{Assumption 4: Fuel Range Impacts}

The potential need for interim, en-route fueling was not a problem for either agency; each has its own on-site fueling facility. There was no attribution to maintenance for a road call to provide refueling (or "rescue") service because planning strategies have eliminated that type of road call.

The fuel range on the Orion buses is specified to be at least 350 miles for equity to a diesel bus. Range can be less due to high ambient temperatures combined with $\mathrm{CNG}$ heat of compression and air-conditioning use.

Various management strategies were employed when routes were longer than the range. For example, rather than using a maintenance servicing truck, a coach operator may have driven out to the relief point in a fully fueled bus and had the relieved operator return to base in the bus that was lower on fuel. Or, coach operators may have exchanged buses mid-route when one was traveling back to base. These options would then be reflected in operating cost rather than maintenance cost.

It is crucial for management to think through the mileage and bus range of each line and plan dispatch strategy accordingly to avoid problems. Dispatchers surveyed for this study acknowledged it was an easy process to learn and soon became standard procedure. 


\section{Assumption 5: Training Maintenance Personnel}

Training cost is not a factor of this report because of its many variances. The agencies shared the philosophy that training is part of "business as usual" and would apply to any fuel-bus configuration. Training is further discussed in the Additional Investment in Switch to CNG section (below).

\section{Assumption 6: Special Projects}

During the study period, SunLine actively assisted the clean fuels industry's efforts to advance developing technology by becoming a beta test site for commercialization via field demonstration. The labor involved in tracking those specific projects and any impact on parts have been deducted from the final analysis to remove the potential to skew results.

\section{Assumption 7: Extrapolation of Capital Cost Recovery}

The only portion of capital investment considered is the incremental cost of a CNG bus over a similar diesel bus. In calculating capital recovery periods, the cost of mid-life rebuild has been omitted since CNG substantially reduced engine wear.

\section{Description of Cost Categories}

As was shown in Public Transportation Alternative Fuels...A Perspective for Small Transportation Operations (Booz-Allen and Hamilton, Inc. 1992) use of:

gaseous fuels will potentially allow less maintenance and greater engine durability than operation with liquid fuels. This is because of the elimination of formation of deposits on the fuel injector tip, ring grooves, piston bowl, and other combustion chamber surfaces. Oil change frequency is longer because of the reduction of formation of acidic products of combustion. Gaseous fuels will not dilute the lubricating oil, accelerating ring, cylinder, and bearing wear.

Both agencies found this to be true, as can be seen in the comparison of 
CNG and diesel maintenance costs (Table 2 and Figure 1). After switching to a CNG fleet in 1994, SunLine had no diesel costs. RT, however, continued to operate diesel and $\mathrm{CNG}$ vehicles, thus enabling costs to be compared. Following is a discussion of 1997 statistics in Figure 1 and Table 2.

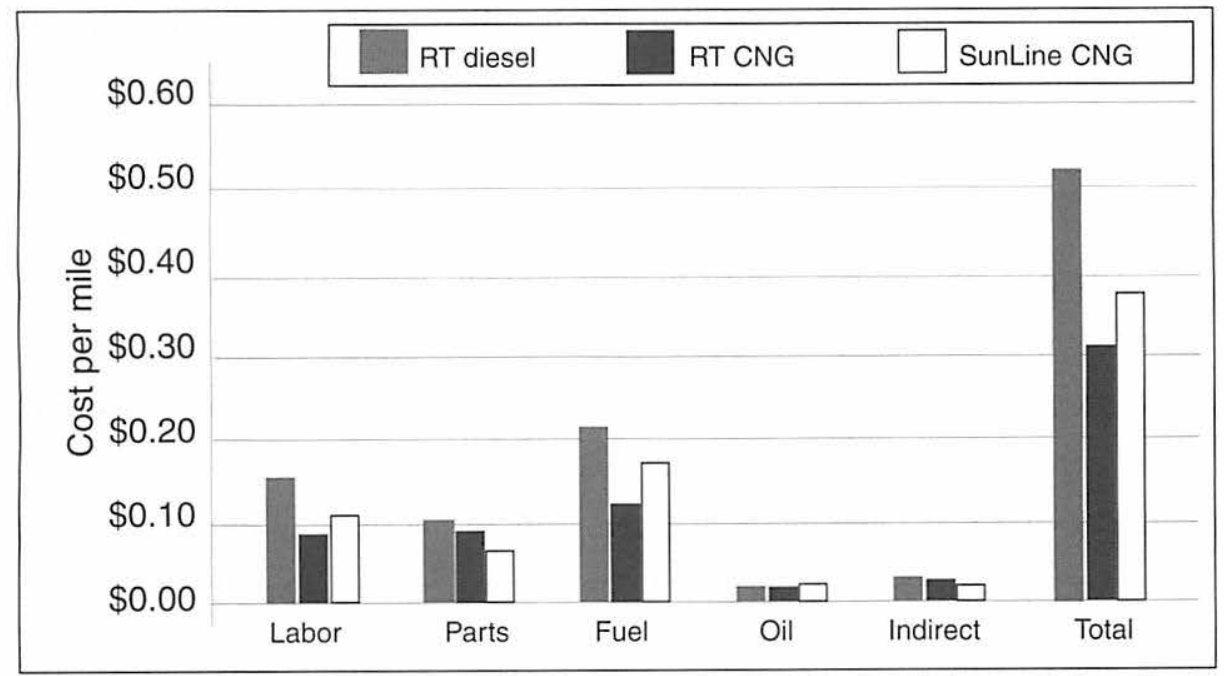

Figure 1. FY 1997 CNG vs. diesel cost per mile

\begin{tabular}{|l|c|c|c|}
\hline \multicolumn{2}{|c|}{ Table 2 } \\
\hline & \multicolumn{2}{c|}{ FY1997 CNG vs. Diesel Cost per Mile } \\
\hline Cost Category & $R T$ & SunLine & Diesel \\
\hline Labor & $\$ 0.087$ & $\$ 0.111$ & $R T$ \\
\hline Parts & 0.088 & 0.061 & $\$ 0.160$ \\
\hline Fuel & 0.122 & 0.178 & 0.110 \\
\hline Oil & 0.006 & 0.012 & 0.223 \\
\hline Indirect & 0.019 & 0.015 & 0.007 \\
\hline Total & $\$ 0.322$ & $\$ 0.377$ & 0.019 \\
\hline
\end{tabular}

\section{Maintenance Labor}

Labor costs were computed for mechanics with chargeable time against a specific bus. Graffiti removal is included by SunLine in the "labor" and "parts" categories (body/glass). No administrative time is computed in this cost. 


\section{Maintenance Parts}

Maintenance parts were consistent for both agencies, although coding for computer input varied somewhat. All parts chargeable to a specific bus were included. In general, categories included: heating/ventilation/air-conditioning, body/glass, head sign, wheelchair lift, fare box, brakes, suspension, tires, driveline, cranking/charging, electrical, engine/transmission cooling, preventive maintenance, accident, and vandalism.

\section{Fuel}

The cost of compression (capital, electricity, and maintenance) was not included in Table 2 and Figure 1. RT owns 100 percent of its fueling facility; SunLine owns 25 percent of one facility and 90 percent of another facility. These percentages were used in fuel cost calculations. Table 3 is a listing of fuel prices for CNG and diesel over the years of the study. While RT's diesel buses averaged 3.51 miles per gallon, its most recent mileage for CNG buses was 3.07; SunLine's was 3.09 miles per equivalent gallon.

\begin{tabular}{|c|c|c|c|}
\hline \multicolumn{4}{|c|}{ Table 3 } \\
\hline & \multicolumn{3}{|c|}{ Fuel Prices (per gallon equivalent) } \\
\hline Year & $R T$ & SunLine & Diesel \\
\hline 1995 & $\$ 0.283$ & $\$ 0.538$ & $\$ 0.692$ \\
\hline 1996 & $\$ 0.380$ & $\$ 0.600$ & $\$ 0.735$ \\
\hline 1997 & $\$ 0.402$ & $\$ 0.551$ & $\$ 0.599$ \\
\hline
\end{tabular}

\section{Oil}

This category included only the cost of oil, while other associated preventive maintenance costs (e.g., filters and labor) were allocated against parts and labor, respectively. Both agencies monitored oil quality through independent analysis and were able to significantly extend oil change intervals as compared to diesel. 


\section{Indirect Costs}

Indirect costs included "bench stock," overhead, and minor parts such as bulbs, fuses, and hoses which are generally low cost and not charged to specific buses. Over several years, these costs can vary dramatically depending on opportunities for bulk purchases, fleet diversity, and specific fleet issues. Although these costs were a minor portion of the overall cost, sometimes varying accounting procedures can affect this type of line item.

\section{Summary of Results}

In 1997, CNG buses saved RT over \$1 million in fuel, maintenance, parts, and hazardous waste disposal, a 38 percent per mile reduction over the cost of their diesel buses. This represented an approximate cost savings of $\$ 0.197$ per mile over 5.7 million miles with 136 buses. That same year, SunLine saved approximately $\$ 213,000$, or $\$ 0.142$ per mile over 1.5 million miles with 34 CNG buses-a 27 percent reduction.

\section{Maintenance Cost Savings Analysis}

This section examines maintenance savings in the FY1997 category costs and year-to-year costs.

\section{FY1997 Category Costs}

RT's labor and fuel costs for the older diesel buses were nearly twice that for CNG buses; parts were 25 percent more. Indirect costs and oil remained approximately the same during the reporting period since RT had not yet decreased the frequency of oil changes for the CNG buses. Oil change frequency has since gone from 8,000 miles to 10,000 miles, compared to 6,000 miles for diesel.

Similar to RT, SunLine's cost savings were seen in fuel, maintenance, and parts. Oil changes occurred every 6,000 miles while the buses were under warranty. Oil changes are now performed every 12,000 miles and are carefully monitored by analysis. 
The total cost-per-mile differences between the two transit agencies can be attributed to various factors. SunLine has a particularly aggressive preventive maintenance (PM) program due in large part to its desert climate. Blowing sand is a daily occurrence and vehicles must be cleaned thoroughly. As a result, SunLine's PM costs (labor and materials) account for 23 percent of the budget as opposed to 16 percent at RT. SunLine also uses each vehicle approximately 3 percent more than RT in revenue service.

Indirect costs were slightly higher for RT than for SunLine. The diversity of its fleet required more overhead in bench stock/small parts.

\section{Year-to-Year Costs}

Savings could be attributed, in part, to the newness of the CNG buses, especially while the manufacturer's warranty covered some maintenance costs.

As expected from the data shown in Table 4, all of the buses showed increasing annual expense as the fleets aged. Although there were expected cost savings in the first years on CNG due to warranty coverages, the margin of cost reductions continued to grow over diesel. Figure 2 represents the rate at which costs grew by comparing the slope of trending costs. Diesel expenses climbed 16 percent from 1995 to 1997, while CNG expenses went up 11 percent over the same period for RT. That is even more significant when considering RT reduced its diesel fleet by 36 percent, increased the new CNG fleet by 30 percent over the same time frame, and the diesel buses incurred about 50 percent less miles each year than the $\mathrm{CNG}$ buses.

\begin{tabular}{|l|l|c|c|c|}
\hline \multicolumn{5}{|c|}{ Table 4 } \\
\hline & & \multicolumn{3}{|c|}{ Dollars per 1,000 Miles } \\
\hline Fuel Type & Agency & FY1995 & FY1996 & FY1997 \\
\hline Diesel & RT & 447 & 466 & 519 \\
\hline CNG & RT & 290 & 294 & 322 \\
\hline & SunLine & 366 & 343 & 377 \\
\hline
\end{tabular}




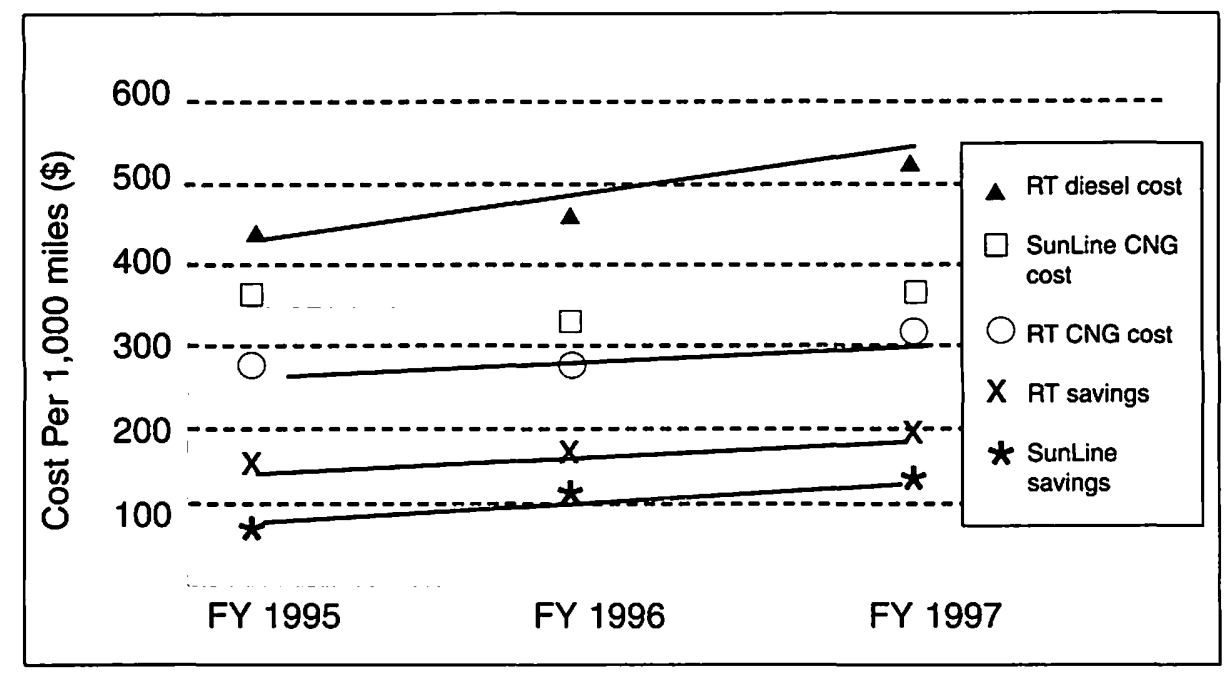

Figure 2. Trend comparisons of costs and savings

SunLine's higher expenses in FY1995 than in the next two years can be attributed to two situations. First, a pressure relief device (PRD) failure ${ }^{1}$ in December 1994 required removal and replacement of PRDs for the total fleet. That event contributed a cost of vented fuel loss to depressurize the storage system and increased mechanic time to accomplish the upgrade to newer PRDs (RT upgraded in FY1997). Second, in January 1995, SunLine opened another operating division that required the additional expense of mobile fueling of the fleet until a fixed-site compressor station was installed.

The important conclusion depicted here is that the reduced rate of CNG cost growth may indeed be an indicator of lower life-cycle costs as addressed in the cost category descriptions and the increasing cost savings shown in Table 5.

\section{Additional Savings}

In California, hazardous waste must be carried away for disposal-a costly endeavor. Because four-stroke, spark-ignited engines remain cleaner in the absence of heavy particulate matter, they neither require steam cleaning as fre- 


\begin{tabular}{|l|c|c|c|}
\hline \multicolumn{4}{|c|}{ Yable 5 } \\
& & \multicolumn{3}{c|}{ Dollars per 1,000 Miles } \\
\hline & FYl995 & FY1996 & FY1997 \\
\hline Agency & 157 & 172 & 197 \\
\hline RT & 81 & 123 & 142 \\
\hline SunLine & & & \\
\hline
\end{tabular}

quently as diesel engines nor as many oil changes. As a result, both RT and SunLine experienced significant cost savings in hazardous waste disposal. Cleanup costs in the shop and parking areas were also substantially less.

SunLine's hazardous waste disposal costs decreased approximately 72 percent after removing diesel buses from the fleet. RT's hazardous waste costs decreased by one-third. That percentage is expected to increase as more diesel buses are replaced by $\mathrm{CNG}$ vehicles.

Road calls were not compared because of the diversity of reporting procedures between the two agencies. For example, the Federal Transit Administration (FTA) does not specify that a malfunctioning air conditioner is a road call, but both agencies count these as road calls because of climatic conditions. Still, neither agency experienced a significant number of CNG-systemrelated road calls.

The transit industry diesel average is approximately 4,000 miles between road calls for all categories. Even with variances in reporting between the two agencies, the differences are impressive. RT's most recent figures showed the CNG bus average exceeded 8,500 miles compared to 6,200 miles between road calls for its older diesel buses. SunLine's most recent average exceeded 11,000 miles. SunLine's advantage can be attributed to an innovative practice of a joint inspection by the operator and mechanic when the bus returns from service each day. This reduces the potential of unreported problems producing road calls. 


\section{Incremental Cost Payback}

Until the manufacturing volume of $\mathrm{CNG}$ buses begins to match the volume of diesel buses, the incremental cost of a CNG-equipped bus will be higher (currently between $\$ 35,000$ and $\$ 50,000$ more per unit). At the rate of savings experienced during the first three years of operation, the payback of the incremental costs would occur midway through the life of the buses. Table 6 shows the payback calculated at a $\$ 50,000$ incremental cost per unit without consideration of life-cycle cost factors.

\begin{tabular}{|l|c|c|c|c|c|c|}
\hline \multicolumn{7}{|c|}{ Table 6 } \\
Payback of Incremental Costs \\
\hline & $\begin{array}{c}\text { Number of } \\
\text { Buses }\end{array}$ & $\begin{array}{c}\text { Incremental Cost } \\
\text { per Bus }\end{array}$ & $\begin{array}{c}\text { Savings } \\
\text { per Year }\end{array}$ & \multicolumn{3}{|c|}{ Payback $^{a}$} \\
\cline { 4 - 7 } & 136 & $\$ 50,000$ & $\$ 1,122,900$ & $\$ 0.197$ & 6.1 & 253,807 \\
\hline RT & 34 & $\$ 50,000$ & $\$ 213,000$ & $\$ 0.142$ & 8.0 & 352,113 \\
\hline SunLine & &
\end{tabular}

a. FTA guideline for the planned life of a bus is 12 years or 500,000 miles.

All information indicated $\mathrm{CNG}$ will have a favorable reduction in lifecycle costs. RT sought to find out whether its fleet would need the $\$ 3,000$ to $\$ 4,000$ mid-life engine rebuild normally required for diesel engines at 250,000 miles. Cummins West, Inc., analyzed internal wear factors to assess engine durability during disassembly of an RT engine that had 296,628 miles. The engine was found to be in very good condition and no problems were discovered that would have prevented it from continuing to operate in the fleet. The internal wear report noted that the bearings could easily last double the mileage, the crankshaft was reusable without rework, the pistons were visually in "new" condition, and the oil pump was in excellent condition. No signs indicated the need for a mid-life rebuild.

\section{Additional Investment in Switch to CNG}

Both agencies experienced initial costs of fuel station installation, facility modifications, and training for both mechanics and operators. Other than the 
fuel station capital cost recovery in the price of fuel, these costs were not factored into the cost-per-mile comparisons.

\section{Fueling and Maintenance Facilities}

SunLine spent $\$ 1.47$ million to design and construct its CNG fueling facility and adapt its maintenance facility. In partnership with Pickens Fuel Corp., SunLine operates a public access 1,200-standard cubic feet per minute (scfm) fuel station with two compressors. SunLine has a 25 percent ownership share and receives credits for all fuel sales; therefore, some of the capital costs are offset by the volume of sales to neighboring public and private fleets. Facility renovations included automated makeup air ventilation integrated into gas detection/alarm systems of 12 sensors for automatic activation of the new mechanical exhaust fans, explosion-proof electrical conduit, sealed sulfur lighting, and totally enclosed heaters.

RT spent $\$ 3.5$ million to design and construct its $\mathrm{CNG}$ fueling facility and adapt its maintenance facility. This included three compressors, dehydrators, buffer vessels, dispenser/control units, control room, and emergency shutdown (ESD) system. RT's design, similar to SunLine's, incorporated 28 gas/fire sensors that detect the presence of gas, and increased shop airflow through the installation of several new ventilation systems, both electric and passive.

Many of these up-front facility modification costs were incurred for safety reasons, and a vast array of choices exists between regulatory jurisdictions in interpreting guidance for the acceptable level of mitigation versus the potential for a hazardous occurrence.

\section{Mechanic Training}

SunLine's mechanics attended 100 hours of training at College of the Desert, which cost approximately $\$ 84,000$ in mechanic wages and benefits. RT invested between $\$ 27,000$ and $\$ 30,000$ in labor costs to retrain its mechanics.

As with any relatively new product, personnel needed to be trained for the introduction of the new technology to be successful. SunLine and RT firmly 
believe the positive results shown in this study are directly related to thorough training practices. For training to be effectively implemented, top management must be committed to the alternative fuel and accept lost productivity during the transition period.

\section{Costs of New Technology and the Payback}

As discussed in the Maintenance Cost Savings Analysis section, both agencies replaced PRDs, which affected expenses. Following this study, in 1998, RT began replacing its EDO brand cylinders because of a leakage problem, whereas cylinders usually last 15 years.

Because both agencies committed to procure more CNG vehicles over time, it would have been inaccurate to load the up-front infrastructure costs against the initial vehicles. So the up-front costs incurred in fueling and maintenance facilities were not calculated here in terms of payback. In SunLine's case, public access infrastructure supports paratransit and nonrevenue vehicles as well as a variety of local government vehicles and heavy-duty refuse trucks. RT's CNG bus fleet is growing each year and will be 100 percent CNG in the next few years. The greater the number of vehicles using the infrastructure, the lower those costs are per vehicle and per mile of operating costs over time.

However, if the infrastructure costs of fueling and maintenance facilities were charged against the original fleets of buses, payback in operational savings within the vehicle life expectancy would still occur. RT's payback would be extended to just over 9 years; SunLine's payback would be extended to just over 11 years.

Infrastructure is a substantial cost, but one that can be either offset by making the fueling facility a profit center (as SunLine has done) or avoided by fueling off-site. Another way to look at the cost is to determine the cost of a diesel fueling facility and the ongoing facility costs.

\section{Policy Implications and Conclusions}

The savings resulting from CNG buses help maintain an equitable pace 
with inflation, enabling both agencies to plan for vehicle replacements and possibly to add service as the stability of future funding allows.

Lower maintenance costs are attributable to thorough mechanic training. There also appears to be some longevity advantage for CNG life-cycle cost reduction because of reduced engine wear due to fewer engine deposits, absence of engine knock, better oil life, and longer life of reciprocating engine components. The FTA's standard 12-year replacement cycle could potentially be extended with maintenance practices concurrently improving chassis life expectancy (in favorable climatic environments). Particulate matter and other harmful emissions from $\mathrm{CNG}$ buses are greatly reduced over their diesel counterparts.

Prior studies have indicated the operating costs of CNG buses are generally higher or about the same as diesel, but the number of CNG buses compared was much smaller than the number of diesel vehicles. The cost to operate five CNG buses at Pierce Transit was $\$ 0.28 /$ mile and five CNG buses at Metro-Dade was $\$ 0.55 / \mathrm{mile}$, as reported in Alternative Fuel Transit Buses, Final Results from a Vehicle Evaluation Program (National Renewable Energy Laboratory 1996). The NREL study was closely matched with diesel controls. RT and SunLine's data fall within the best and worst range of that report but showed much better results over diesel, which could be partly attributed to the age of RT's diesel engines.

RT will continue to procure buses with CNG engines to meet the goal of replacing its entire fleet by 2003 . SunLine will continue to purchase only CNG or new clean technology replacement vehicles for service operation and support. Both agencies will pursue all subsequent improvements to CNG technology, with the goal of providing more reliable vehicles in a cleaner environment.

Use of CNG technology also improves the image of mass transit. Transit buses are usually thought of as belching black smoke. No driver enjoys being behind a bus in slow-moving traffic. CNG buses emit no black smoke partic- 
ulates (which stain the buses and make them appear unattractive), plus are also quieter to operate. This presents a more appealing perspective of bus riding; hopefully encouraging more individuals to use mass transit and take community pride in their transit systems.

In August 1998, California became the first state in the nation to name diesel exhaust as a toxic air contaminant—one that can cause cancer and other diseases. With growing environmental and health concerns over diesel, both agencies are sending strong messages to the citizens of their communities that alternative fuels help maintain a clean environment. Elected officials at both public agencies share a commitment to use alternative fuels and assist other local partners in using alternative fuels. As a result, area sanitation/refuse haulers, water districts, car rental agencies, shuttle services, and municipalities are now using CNG. Both agencies are active participants in their regions' U.S. Department of Energy Clean Cities programs.

CNG buses support the economies of Sacramento as the California state capital, and the Coachella Valley as an international resort destination. Air quality is an important destination criteria for tourists and visitors.

Both Sacramento RT and SunLine have found a win-win situation in CNG with significant maintenance savings and emission reductions. It is more economical to power buses on $\mathrm{CNG}$ than diesel and both communities take pride in transit's leadership in promoting cleaner air.

\section{Acknowledgments}

The authors wish to thank staff from the following organizations for their thoughtful review of the article before its final publication: Clean Air Now (Riverside, California), Gas Research Institute (Chicago, Illinois), INFORM (New York, New York), National Renewable Energy Laboratory (Golden, Colorado), and Natural Gas Vehicle Coalition (Washington, D.C.).. 


\section{Endnote}

1. SunLine had a high-pressure PRD failure inside the maintenance garage leading to a burn of vented fuel, causing no harm to personnel or damage to buses, but minor facility damage. The extreme cost impact was due to hazardous material cleanup caused by fire suppression sprinkler flow into, and subsequent overflow of, waste oil reservoirs creating a massive oil spill on the property. For more details on this incident, see "Safety First: Lessons Learned from a Pressure Relief Device Failure," Natural Gas Fuels Magazine, November 1995.

\section{References}

Booz-Allen and Hamilton, Inc. 1992. Public Transportation alternative fuels...A perspective for small transportation operations, pp. 2-62.

National Renewable Energy Laboratory. October 1996. Alternative fuel transit buses, final results from a vehicle evaluation program.

\section{About the Authors}

Chief Operating Officer CAMERoN BEACH (cbeach@sacrt.com) is responsible for over 600 employees, a $\$ 52$ million budget, and all rail and bus transportation at RT. In his 36-year transit career, Mr. Beach has worked for both public and private sector providers of public transportation.

For the past 14 years, MichAEL COOKE (mcooke@sacrt.com) has served as maintenance manager at RT. He is responsible for the upkeep of a 220-bus fleet, a staff of more than 100 , and a department budget of $\$ 11$ million. He has been actively involved in every phase of RT's conversion to CNG.

Assistant general manager for SunLine Transit Agency at the time the study was done, TRACY DALY (daly@scrra.net) was involved in nearly every aspect of the agency's conversion to CNG. In August 2000, she joined the staff of Metrolink in Los Angeles, California, as assistant executive officer. 
BRUCE FINLEY (BFinley@naF4.afres.af.mil)is a mechanical engineer specializing in alternate fuels management. An engineering manager at SunLine Transit Agency for five years, Mr. Finley supervised the agency's Alternate Fuels Equipment Division during its conversion to CNG. Prior to joining SunLine, he had 12 years ballistic missile research and development experience for the U.S. Air Force; he continues to serve as an air force major.

A consultant to the transit industry, Cis Leroy (cisleroy@aol.com) specializes in local and regional transit planning and grants administration. During her 20-plus-year transit career, she has held managerial/analyst positions in large and small systems and has helped numerous bus, rail, and paratransit agencies with short- and long-range plans. 